Pacific Journal of Mathematics

CHARACTERIZATIONS OF INFINITE-DIMENSIONAL AND 


\title{
CHARACTERIZATIONS OF INFINITE-DIMENSIONAL AND NONREFLEXIVE SPACES
}

\author{
M. Edelstein AND L. KeEner
}

\begin{abstract}
Infinite-dimensional, resp. nonreflexive spaces are characterized in terms of subsets having a finite visibility property without being starshaped.
\end{abstract}

1. Introduction. A well-known result of Smulian [4] states that every nonreflexive normed linear space contains a decreasing sequence of nonempty closed and bounded convex sets whose intersection is empty. This result was used by V.L. Klee [1] to show that a normed linear space is nonreflexive if, and only if, it contains a decreasing sequence of closed and bounded starshaped sets whose intersection is empty. Also proved by Klee [2] is the following. Theorem [Klee]. Every infinite dimensional normed linear space contains a decreasing sequence of unbounded but linearly bounded closed convex sets whose intersection is empty. Here, a set is called linearly bounded if each straight line intersects it in a bounded set.

In the present paper other characterizations of infinite-dimensional, and of nonreflexive spaces are given which are similar in spirit and not unrelated to those mentioned above. To this end use is made of the notion of finite visibility. A set $S$ is said to have the finite visibility property, f.v.p. for short, if for any finite $F \subset S$ there is an $x \in S$ such that the line segment $[x, y]$ is contained in $S$ for all $y$ in $F$. As customary a set $S$ is called starshaped if an $s \in S$ exists such that the above condition is satisfied with $s$ replacing $x$ and $S$ replacing $F$. A well-known theorem of Krasnoselski [3] implies that in a finite dimensional normed linear space $X$ if $S$ is closed and bounded and has f.v.p. then $S$ is starshaped. (In fact, if $\operatorname{dim} X=n$, and card $S \geqq n+1$, then the above mentioned theorem holds if the hypothesis is satisfied for all $F$ with card $F=n+1$.) A previous version of this paper was mainly concerned with showing that in some Banach spaces a weakly closed bounded set may have f.v.p. without being starshaped. The broader scope of the present paper is due to suggestions made by Professor Klee in a personal communication, in which he conjectured the two theorems of this paper and directed us to relevant passages in some of his works. It is indeed a pleasure to acknowledge his help.

2. Preliminary results.

Lemma 1. A compact subset $S$ of a Hausdorff linear topological 
space $X$ is starshaped if it has the finite visibility property.

Proof. For $x \in S$, let $S_{x}=\{y \in S:[x, y] \subset S\}$, a closed set. The family $\left\{S_{x}: x \in S\right\}$ has the finite intersection property by f.v.p. so $\cap S_{x} \neq \varnothing$ by compactness, and $S$ is starshaped.

Lemma 2. Let $E$ be a closed subspace of a normed linear space $X, S$ a closed convex linearly bounded set in $E$ and $x$ a point in $X \sim E$. Then $K=\operatorname{co}\{\{x\} \cup S\}$ is closed.

Proof. Let $y \in \bar{K}, y \neq x$, and let $F$ be the subspace spanned by $x$ and $S$. Clearly $y \in F$. Thus if $R$ is the ray emanating from $x$, through $y$, i.e. $R=\{z \in X: z=x+\alpha(y-x), \alpha \geqq 0\}$, then $R$ is contained in $F$. Moreover, $R$ cannot be parallel to $E$, for if parallel, then with $w \in S, R^{\prime}=\{z \in X: z=w+\alpha(y-x), \alpha \geqq 0\}$ is contained in $E$ and by linear boundedness there is a $w^{\prime} \in R^{\prime} \sim S$. But then $w^{\prime}$ and $S$ can be separated by a hyperplane $H \subset E$, relative to $E$. The subspace spanned by $H$ and $x$ clearly determines a closed halfspace of $F$ which contains $\{\{x\} \cup S\}$ and is disjoint from $y$, leading to a contradiction, since $y \in \bar{K}$. Suppose now that $u$ is the point of intersection of $R$ and $E$. It suffices to show that $u \in S$. If not, then there is an open ball $B$ about $u$ which is disjoint from $S$ and co $\{\{x\} \cup \mathrm{B}\}$ is a neighborhood of $u$ which contains no point of the form $\lambda x+$ $(1-\lambda) s$ for any $\lambda, 0 \leqq \lambda<1$ and $s \in S$. This is impossible since $y \in \bar{K}$. Hence $y \in K$ and $K=\bar{K}$ as claimed.

Lemma 3. Let $x$ be a normed linear space, $E$ a closed subspace of $X$ and $l$ a line skew to $E$, i.e. $l$ neither intersects $E$ nor is parallel to any line of $E$. Let $\left\{C_{k}: k=1,2, \cdots\right\}$ be a decreasing sequence of closed convex subsets of $E$ and $\left\{p_{k}: k=1,2, \cdots\right\}$ a sequence on $l$ converging to some $p_{0}$. Let $K_{i}=\operatorname{co}\left\{\left\{p_{i}\right\} \cup C_{i}\right\}$ for $i \geqq 1$ and $K_{0}=$ co $\left\{\left\{p_{0}\right\} \cup C_{1}\right\}$.

Then $S=\mathbf{U}\left\{K_{i}: i=0,1, \cdots\right\}$ is weakly closed. If, in addition, $C_{1}$ is linearly bounded then so is $S$.

Proof. To prove that $S$ is weakly closed let $x \in X \sim S$. Then $x \notin K_{0}$, which is closed by Lemma 2 , and convex. Thus there is a hyperplane $H$ such that $x \in H^{+}$and $K_{0} \subset H^{-}$where $H^{+}$and $H^{-}$are open halfspaces determined by $H$. Let $n_{0}$ be such that $p_{n} \in H^{-}$ whenever $n>n_{0}$. Then, for such $n, K_{n} \subset H^{-}$since $\left\{\left\{p_{n}\right\} \cup C_{n}\right\} \subset H^{-}$. On the other hand, as $\mathrm{U}\left\{K_{i}: i \leqq n_{0}\right\}$ is weakly closed there is a weak neighborhood $W$ of $x$ which is disjoint from it. It follows that $W \cap H^{+}$is a weak neighborhood of $x$ which is disjoint from $S$. Hence $S$ is weakly closed. To prove linear boundedness observe first that, 
as can be readily verified, in finite dimensional spaces boundedness and linear boundedness are equivalent for closed convex sets. If now $l_{1}$ is a line in $X$ let $L$ be the subspace spanned by $l \cup l_{1}$. Then $L \cap C_{1}$ is bounded and closed and $l_{1} \cap S$ is contained in the compact set

$$
\operatorname{co}\left\{\left\{p_{k}: k=0,1, \cdots\right\} \cup\left(C_{1} \cap L\right)\right\}
$$

and therefore bounded. Hence $S$ is linearly bounded, as asserted.

LEMma 4. Let $X$ be a linear space, $E$ a subspace of $X$ and $l$ a line in $X$ which is skew to $E$. If $p, q \in l, p \neq q$, and $A, B$ are convex subsets of $E$ then

$$
\operatorname{co}\{\{p\} \cup A\} \cap \operatorname{co}\{\{q\} \cup B\}=A \cap B .
$$

Proof. Let $x \in \operatorname{co}\{\{p\} \cup A\} \cap \operatorname{co}\{\{q\} \cup B\}$. It suffices to show that $x \in A \cap B$. If this were not the case then $x \in[p, a) \cap[q, b)$ for some $a \in A$ and $b \in B$, with $a \neq b$. But then $a, b, p, q$ would have to be coplanar against the assumption that $l$ is skew to $E$.

Lemma 5. Let $X$ be a linear space, $E$ a subspace of $X$ and $l$ a line in $X$ which is skew to $E$. Suppose $p_{i}: i=1,2, \cdots$ is a sequence of distinct points on $l$. Let $C_{i} \subset E$ be convex, $K_{i}=\operatorname{co}\left\{\left\{p_{i}\right\} \cup\right.$ $\left.C_{i}\right\} i=1,2, \cdots$ and $S=\bigcup\left\{K_{i}: i=1,2, \cdots\right\}$. Then $S$ is starshaped if, and only if, $\bigcap\left\{C_{i}: i=1,2, \cdots\right\} \neq \varnothing$ and $S$ has f.v.p. if, and only if, $\left\{C_{i}: i=1,2, \cdots\right\}$ has the finite intersection property.

Proof. If $l^{\prime}$ is a line such that $l^{\prime} \cap\left(K_{j} \sim C_{j}\right) \neq \varnothing$ then card $\left(l^{\prime} \cap\right.$ $\left.K_{i}\right) \leqq 1$ for any $i \neq j$. Indeed, if for some $i \neq j l^{\prime} \cap K_{i}$ contains two or more points then $l^{\prime}$ is contained in $L_{i}$, the linear span of $K_{i}$; but then $l^{\prime} \cap\left(K_{j} \sim C_{j}\right)=\varnothing$ since $L_{i} \cap K_{j} \subset C_{j}$ by the preceding lemma. Hence $\left[u, p_{i}\right]$, with $u \in K_{j} \sim C_{j}$ and $i \neq j$, is not contained in $S$ as card $\left(\left[u, p_{i}\right] \cap S\right) \leqq \boldsymbol{\aleph}_{0}$. Thus $\mathbf{U}\left\{\left[u, p_{m}\right] \subset S: m \in M\right\}$, where $M$ is a set of two or more positive integers, implies that $u \in \bigcap\left\{C_{m}: m \in M\right\}$. It follows that for $S$ to be starshaped it is necessary that $\bigcap\left\{C_{i}: i=\right.$ $1,2, \cdots\} \neq \varnothing$ and for it to have f.v.p. $\left\{C_{i}: i=1,2, \cdots\right\}$ has to have the finite intersection property.

For the converse note that $u \in \bigcap\left\{C_{i}: i=1,2, \cdots\right\}$ implies $S_{u}=S$ and if $F \subset S$ is finite then, for $N$ sufficiently large, $F \subset \cup\left\{K_{i}: i=\right.$ $1,2, \cdots\}$ and this last set is contained in $S_{u}$ for any $u \in \bigcap\left\{C_{i}: i=\right.$ $1,2, \cdots, N\}$.

\section{Main results.}

Theorem 1. A normed linear space is infinite-dimensional if, 
and only if, it contains a linearly bounded, weakly closed subset $S$ which has the finite visibility property but fails to be starshaped.

Proof. If $X$ contains a set $S$ with the stated properties then by the Krasnoselski theorem [3] $X$ must be infinite-dimensional.

Assume now that $X$ is infinite-dimensional and $E$ is a closed subspace of $X$ of codimension 2. By the theorem of Klee quoted in the introduction, $E$ contains a decreasing sequence $\left\{C_{k}: k=1,2, \cdots\right\}$ of nonempty, closed, linearly bounded subsets whose intersection is empty. Let $l$ be a line which is skew to $E$ and $\left\{p_{k}: k=1,2, \cdots\right\}$ a sequence of distinct points on $l$ converging to $p_{0} \in l$. Let $K_{i}, i=$ $0,1, \cdots$ and $S$ be as in Lemma 3 . Then $S$ is weakly closed and linearly bounded by that lemma. By Lemma $4 S$ has f.v.p. but fails to be starshaped.

THEOREM 2. A normed linear space $X$ is nonreflexive if, and only if, it contains a set $S$ which is bounded, weakly closed, has the finite visibility property but fails to be starshaped.

Proof. If $X$ contains a set $S$ with the stated properties then, by Lemma 1 , it fails to be reflexive.

Assume now that $X$ is nonreflexive and, as in the construction of the proof of Theorem 1, let $E$ be a closed subspace of $X$ of codimension 2 and $l$ a line skew to $E$. Let $\left\{p_{k}\right\}$ be a sequence of distinct points on $l$ converging to $p_{0} \in l$. By the Smulian theorem [3] there exists a decreasing sequence $\left\{C_{k}: k=1,2, \cdots\right\}$ of nonempty, closed and bounded convex sets in $E$ whose intersection is empty. Let $K_{i}$, $i=0,1, \cdots$ and $S$ be defined as in the proof of Theorem 1 . Then the arguments used there apply again to the effect that $S$ is weakly closed, bounded, with f.v.p. but not starshaped.

4. An example in $l_{1}$. The following is an example of a concrete subset of $l_{1}$ having all the properties of the set $S$ of Theorem 2 . Let $S$ consist of all $x=\left(x_{1}, x_{2}, \cdots, x_{n}, \cdots\right) \in l_{1}$ such that

(i) $x_{n} \geqq 0$ for $n=1,2, \cdots$;

(ii) $\|x\|=1$;

(iii) if $x_{2 n} \neq 0$ then $x_{k}=0$ for $1 \leqq k<2 n$.

To show that $S$ has the finite visibility property let $F \subset S$ be finite and $N$ an odd integer which is larger than the index of the first positive coordinate of each member of $F$. If $e_{N} \in S$ has 1 for its $N$ th coordinate then clearly $\left[u, e_{N}\right] \subset S$ for all $u \in F$.

To prove that $S$ is weakly closed let $y=\left(y_{1}, y_{2}, \cdots, y_{n}, \cdots\right) \in l_{1} \sim S$ and assume, as we may, that $\|y\|=1$. Since $y \notin S$, there must be 
positive integers $n$, $k$ such that $k<2 n$ and $y_{k}>0$ and $y_{2 n}>0$. If $u=\left(u_{1}, \cdots, u_{k}, \cdots\right), v=\left(v_{1}, \cdots, v_{2 n}, \cdots\right) \in l_{\infty}$ are such that $u_{k}=v_{2 n}=1$ and all other coordinates $=0$ then

$$
W=\left\{z \in l_{1}: u(z)>0 \text { and } v(z)>0\right\}
$$

is a weak neighborhood of $y$ which is disjoint from $S$. Since boundedness of $S$ is obvious it remains to show that $S$ is not starshaped. If now $u=\left(u_{1}, u_{2}, \cdots, u_{k}, \cdots\right) \in S$ and $u_{k} \neq 0$ then for $x=\left(x_{1}, \cdots, x_{n}, \cdots\right) \in S$ with $s_{2 k}=1$ we have $[u, x] \notin S$.

\section{REFERENCES}

1. V. L. Klee, Convex bodies and periodic homeomorphisms in Hilbert space, Trans. Amer. Math. Soc., 17 (1953), 10-43.

2. - A note on topological properties of normed linear spaces, Proc. Amer. Math. Soc., 7 (1956), 673-674.

3. M. Krasnoselski, Sur un critère pour qu'un domaine soit étoilée, Rec. Math. [Mat. Sbornik] N. S., 19 (1946), 309-310.

4. V. Smulian, On the principle of inclusion in the space of type (B), Mat. Sbornik N. S., 5 (1939), 317-328.

Received December 8, 1974 and in revised form February 5, 1975. This research was supported by the National Research Council of Canada, Grants A-3999 and A-8755.

Dalhousie University, Halifax, Nova Scotia 



\section{PACIFIC JOURNAL OF MATHEMATICS}

\section{EDITORS}

RICHARD ARENS (Managing Editor)

University of California

Los Angeles, California 90024

\section{J. DugundJI}

Department of Mathematics University of Southern California Los Angeles, California 90007

D. Gilbarg and J. Milgram

Stanford University

Stanford, California 94305
University of Washington Seattle, Washington 98105

\section{ASSOCIATE EDITORS}
E. F. BECKENBACH
B. H. NeumanN
F. WolF
K. YoShIDA

\section{SUPPORTING INSTITUTIONS}

\author{
UNIVERSITY OF SOUTHERN CALIFORNIA \\ STANFORD UNIVERSITY \\ UNIVERSITY OF TOKYO \\ UNIVERSITY OF UTAH \\ WASHINGTON STATE UNIVERSITY \\ UNIVERSITY OF WASHINGTON \\ $\stackrel{*}{*} \stackrel{*}{*} \stackrel{*}{ }{ }^{*}$ AMERICAN MATHEMATICAL SOCIETY
}

The Supporting Institutions listed above contribute to the cost of publication of this Journal, but they are not owners or publishers and have no responsibility for its content or policies.

Mathematical papers intended for publication in the Pacific Journal of Mathematics should be in typed form or offset-reproduced, (not dittoed), double spaced with large margins. Underline Greek letters in red, German in green, and script in blue. The first paragraph or two must be capable of being used separately as a synopsis of the entire paper. Items of the bibliography should not be cited there unless absolutely necessary, in which case they must be identified by author and Journal, rather than by item number. Manuscripts, in triplicate, may be sent to any one of the editors. Please classify according to the scheme of Math. Reviews, Index to Vol. 39. All other communications should be addressed to the managing editor, or Elaine Barth, University of California, Los Angeles, California, 90024.

The Pacific Journal of Mathematics expects the author's institution to pay page charges, and reserves the right to delay publication for nonpayment of charges in case of financial emergency.

100 reprints are provided free for each article, only if page charges have been substantially paid. Additional copies may be obtained at cost in multiples of 50 .

The Pacific Journal of Mathematics is issued monthly as of January 1966. Regular subscription rate: $\$ 72.00$ a year (6 Vols., 12 issues). Special rate: $\$ 36.00$ a year to individual members of supporting institutions.

Subscriptions, orders for back numbers, and changes of address should be sent to Pacific Journal of Mathematics, 103 Highland Boulevard, Berkeley, California, 94708.

\section{PUBLISHED BY PACIFIC JOURNAL OF MATHEMATICS, A NON-PROFIT CORPORATION}

Printed at Kokusai Bunken Insatsusha (International Academic Printing Co., Ltd.), 270, 3-chome Totsuka-cho, Shinjuku-ku, Tokyo 160, Japan.

\section{Copyright (C) 1975 by Pacific Journal of Mathematics} Manufactured and first issued in Japan 


\section{Pacific Journal of Mathematics}

\section{Vol. 57, No. $2 \quad$ February, 1975}

Norman Larrabee Alling, On Cauchy's theorem for real algebraic curves with boundary .......

Daniel D. Anderson, A remark on the lattice of ideals of a Prüfer domain ..................

Dennis Neal Barr and Peter D. Miletta, A necessary and sufficient condition for uniqueness of

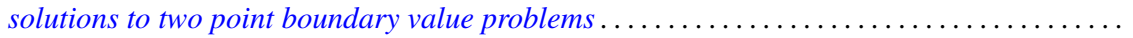

Ladislav Beran, On solvability of generalized orthomodular lattices . . . . . . . . . . ........

L. Carlitz, A three-term relation for some sums related to Dedekind sums . . . . . . . . . .....

Arthur Herbert Copeland, Jr. and Albert Oscar Shar, Images and pre-images of localization

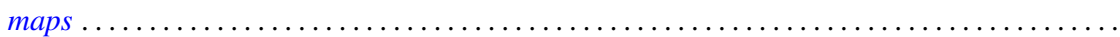

G. G. Dandapat, John L. Hunsucker and Carl Pomerance, Some new results on odd perfect

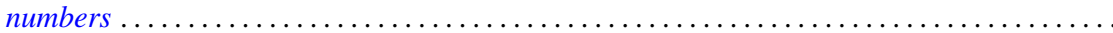

M. Edelstein and L. Keener, Characterizations of infinite-dimensional and nonreflexive

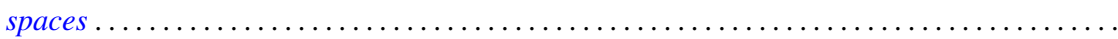

Francis James Flanigan, On Levi factors of derivation algebras and the radical embedding

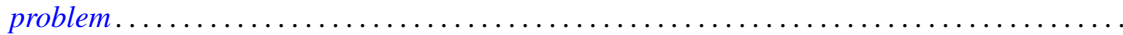

Harvey Friedman, Provable equality in primitive recursive arithmetic with and without

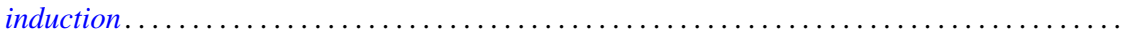

Joseph Braucher Fugate and Lee K. Mohler, The fixed point property for tree-like continua with

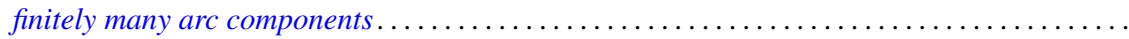

John Norman Ginsburg and Victor Harold Saks, Some applications of ultrafilters in

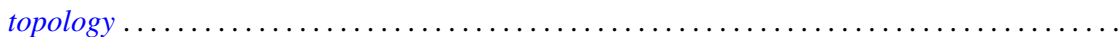

Arjun K. Gupta, Generalisation of a "square" functional equation .....................

Thomas Lee Hayden and Frank Jones Massey, Nonlinear holomorphic semigroups ..........

V. Kannan and Thekkedath Thrivikraman, Lattices of Hausdorff compactifications of a locally

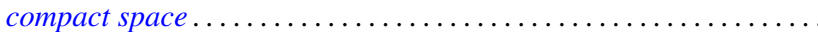

J. E. Kerlin and Wilfred Dennis Pepe, Norm decreasing homomorphisms between group

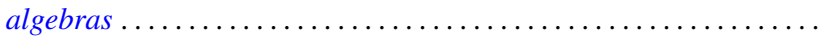

Young K. Kwon, Behavior of $\Phi$-bounded harmonic functions at the Wiener boundary ...

Richard Arthur Levaro, Projective quasi-coherent sheaves of modules .

Chung Lin, Rearranging Fourier transforms on groups...........................

David Lowell Lovelady, An asymptotic analysis of an odd order linear differential equation . . 4475

Jerry Malzan, On groups with a single involution .......................... 481

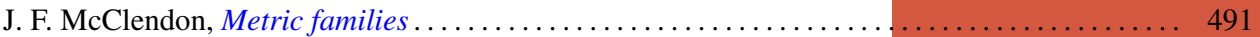

Carl Pomerance, On multiply perfect numbers with a special property .

Mohan S. Putcha and Adil Mohamed Yaqub, Polynomial constraints for finiteness of semisimple rings. .

Calvin R. Putnam, Hyponormal contractions and strong power convergence . . . . . . . . . 531

Douglas Conner Ravenel, Multiplicative operations in $\mathrm{BP} * \mathrm{BP} \ldots \ldots \ldots \ldots \ldots \ldots \ldots \ldots \ldots .539$

Judith Roitman, Attaining the spread at cardinals which are not strong limits . . . . . . . . . 545

Kazuyuki Saitô, Groups of *-automorphisms and invariant maps of von Neumann algebras . . . 553

Brian Kirkwood Schmidt, Homotopy invariance of contravariant functors acting on smooth

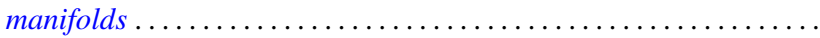

Kenneth Barry Stolarsky, The sum of the distances to $N$ points on a sphere.

Mark Lawrence Teply, Semiprime rings with the singular splitting property.

J. Pelham Thomas, Maximal connected Hausdorff spaces..............

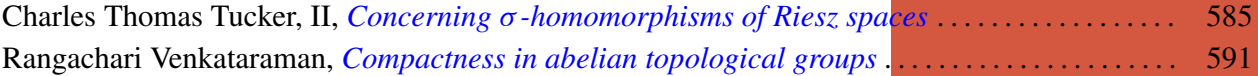

William Charles Waterhouse, Basically bounded functors and flat sheaves . . . . . . . . . . . 597

David Westreich, Bifurcation of operator equations with unbounded linearized part ......... 611

William Robin Zame, Extendibility, boundedness and sequential convergence in spaces of 